Research Article

\title{
Fluidization Analysis of Thickening in the Deep Cone for Cemented Paste Backfill
}

\author{
Haiyong Cheng, ${ }^{1,2}$ Jin Liu, ${ }^{1}$ Shunchuan $W u^{1,2}$ and Xiaoqiang Zhang $\mathbb{D}^{1,2}$ \\ ${ }^{1}$ Faculty of Land Resources Engineering, Kunming University of Science and Technology, Kunming 650093, China \\ ${ }^{2}$ Key Laboratory of Ministry of Education of China for Efficient Mining and Safety of Metal Mines, Beijing 100083, China
}

Correspondence should be addressed to Xiaoqiang Zhang; zhangxiaoqiang@kust.edu.cn

Received 3 April 2020; Accepted 29 June 2020; Published 5 August 2020

Academic Editor: María Criado

Copyright (c) 2020 Haiyong Cheng et al. This is an open access article distributed under the Creative Commons Attribution License, which permits unrestricted use, distribution, and reproduction in any medium, provided the original work is properly cited.

\begin{abstract}
Cemented paste backfill (CPB) can effectively eliminate the risk of dam break in goaf and tailings pond which used tailings waste. Deep cone thickener (DCT) is an efficient machine for the system of paste preparation, and the concentration of slurry at the bottom is high and distributed unevenly, which will cause too much partial resistance and failure of thickener. Focusing on the above problems, fluidization design was conducted by using the fluidization theory. The delivery law of flocs was analyzed, and the isobaric surface was obtained. The equation of pressure and critical velocity of the ideal fluidized bed was acquired by analyzing the relationship between pressure and critical velocity. Based on the characteristics of tailings and distribution of the bonding zone, the arrangement, number, and working mode of spray nozzles were reformed. It is verified that the failure time of thickener decreased from 14 hours to 1 hour and the range of concentration increased from $74 \% \sim 78 \%$ to $78 \%$ $80 \%$, which improved the stability and reliability of DCT. The depth thickening mechanism is obtained, and the thickening method has been improved which provides a theoretical basis for the effective preparation of paste.
\end{abstract}

\section{Introduction}

At present, mine tailings are often discharged into tailings ponds for its cost efficiency and convenience, where solids and liquids are separated by gravity $[1,2]$. However, direct disposal into tailings ponds cannot be widely used in the modern era due to its intrinsic drawbacks [3]. To dispose of mineral tailings in a technical, environmental, and economical way, the cemented paste backfill (CPB) technology is proposed and widely adopted [4-6]. CPB is a complex material composed of multiscale materials produced with dewatered tailings (70-85\% solids by weight), hydraulic binders (3-7\% by dry paste weight), and water $[1,7-10]$. $\mathrm{CPB}$ provides safe, green, and efficient technical guarantee for underground goaf treatment and tailings disposal $[11,12]$. CPB may become the only scheme for safe and green mining of deep resources. The fluidity, rheology, and settling property are the important indexes that affect the preparation of paste [13-15]. Through gravity and chemical and mechanical action, the deep cone thickener can prepare low-concentration tailings into high-concentration tailings for paste filling. Dewatering plays an important role in the thickening performance of tailings slurry [16]. Many scholars have claimed that the dewatering of tailings can reduce the costs of the facility, increase the mineral recovery, and save water [17-19]. Thickened tailing technology is advantageous when used for the saving of water in mines $[20,21]$.

The ordinary thickener and filtration equipment have been widely applied in China with dehydration and thickening technology of unclassified tailings [22, 23], but it cannot satisfy the requirement of high-concentration paste preparation. Deep cone thicker (DCT) is the main equipment of tailings dehydration and thickening for the preparation. According to Jiao et al.'s experimental analysis, the Box-Behnken design in RSM is an appropriate and powerful approach for the optimization of flocculation and settling parameters of nickel tailings slurry [24-26]. Jiao studied the 
shear effect through continuous thickening and computed tomography (CT) scanning tests and revealed the shearingdewatering performance of the tailings bed [27].

The underflow concentration can achieve 75\% 78\% under the condition of less than $30 \%$ of the feed concentration. Failure of thickener happened easily for fluctuation of the feeding quality, and too much partial resistance led to overloading of mud scraping harrow. The influencing time of a failure of thickener was more than $14 \mathrm{~h}$ [28], which seriously affected the filling operation $[29,30]$. The main factor of failure of DCT is high partial concentration, leading to exceeding torsional moment of equipment in the thickener. If the thickener slurry can be homogeneous and fluidized, it will avoid the formation of filter cake at the bottom of the equipment [31]. The above research provides a variety of guidance for the development of tailings thickening, so that tailings with different grading and quality standards can get better underflow concentration through certain technical means. However, for some materials, because of the too fast thickening rate, it is easy to cause accidents such as rake pressing, and the concentration discharge is not stable, which seriously restricts the thickening effect.

In order to improve the homogenization of materials at the cone bottom, based on the fluidized principle, it was proposed that nozzles can be added at the bottom of the harrow [32]. The nozzles could loosen tailings slurry by some media and liquefy the tailings so that the system could restart after harrow halted [33], which can reduce the processing time and improve operational efficiency.

\section{Fluidization Mechanism of Tailings in DCT}

2.1. Mechanism of DCT Discharging Tailings. Tailings deposit at the bottom of the cone in the process of settlement; meanwhile, water segregates from the tailings and flows upon the tailings, and the obvious interface occurs $[34,35]$. The floc structure of ultrafine tailings is formed under the action of flocculating agents, and the floc structure realizes the overall settlement by the gravity. Under the mechanical shear of the rake frame, the closed water is released and the concentration is further increased. At the beginning of discharging tailings, on the one hand, tailings pore water moves down with solid particles. On the other hand, it permeates through the pore space net into tailings discharging spray nozzle [36]. The motion water pressure $P$, which is imposed by water on tailings, is invoked by the velocity difference between the two-phase materials [37].

Therefore, during the tailings discharging process, the flow of the sand body in the DCT will form a tailings discharging funnel, as shown in Figure 1. The funnel develops upward from the discharging spray nozzle [38]. When it expands to a certain height and arrives at the whole section of DCT, we define the volume higher than the section as unclassified tailings flow part, while the lower volume is defined as the funnel part [39]. The tailings in two sides of the funnel are consolidated by the tailings upon them and form a bond zone with high concentration and a certain strength. Because of the permeation of the water

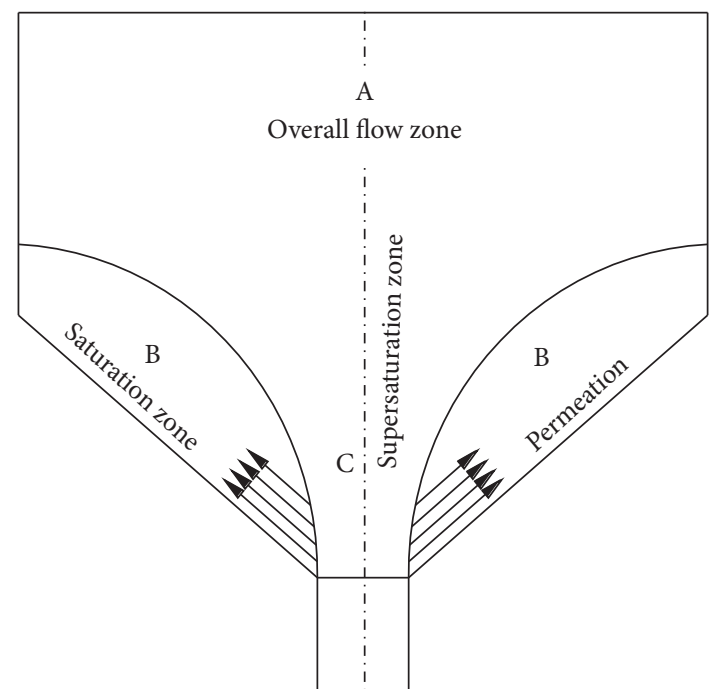

Figure 1: Flow part during deep cone thickener discharging tailings.

flow, the oversaturated water in the $\mathrm{C}$ part permeates into part B. Furthermore, the fluidization range is expanding gradually.

2.2. Pressure Drop in the Fluidized Bed. With setting jet nozzle in DCT, the fluidized medium is pumped to make the granular tailings loose and fluidized. The nozzle is generally arranged at the bottom of the thickener in the form of ring or matrix arrangement. According to the change of bottom pressure, high-concentration tailings are fluidized by spraying high-pressure water or gas through nozzle. Under ideal condition, the relationship between the pressure drop, which resists the flow resistance, and the flow velocity is shown in Figure 2.

When the flow velocity is low, the bed, which is composed of a large number of inert particles, is stationary. The fluid only flows through the particle pore space. In this period, the tailings are fixed bed. With the velocity speeding up, the turbulence capability enhances and the frictional resistance increases, which generates when the fluid flows through the bed, and the pressure drop rises correspondingly, as shown in section $\mathrm{AB}$ of Figure 3 . As the velocity reaches an exact speed, the tailings step into the fluidized phase [40].

During the period of the fluidized bed, the pressure drop whose value is equal to net gravity in a unit area in the whole bed is constant $[3,7,41]$. The CD section in Figure 2 shows the relationship between $\Delta p$ and $U$ in that period. If the fluidized bed velocity decreases, bed height and porous rate reduce, respectively. The relationship of $\Delta p-U$ returns along the DC line. As it reaches point $\mathrm{C}$, the solid particles contact each other and become a motionless stable bed. If the velocity continues to decrease, the variation of bed pressure drop will no longer follow the broken line CBA but align with the line $\mathrm{CA}$. The velocity corresponding to point $\mathrm{C}$ is called as critical fluidized velocity $U_{m f}$, which defines the minimum fluidized velocity. 


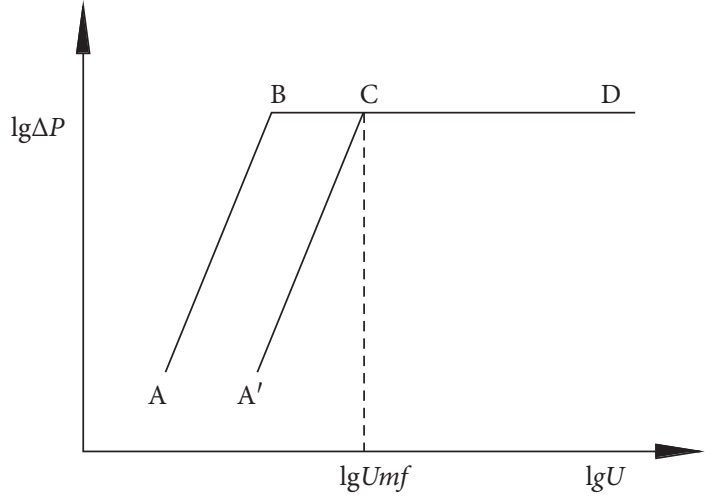

FIgURE 2: The relationship between $\Delta p$ and $U$ in the ideal fluidized bed.

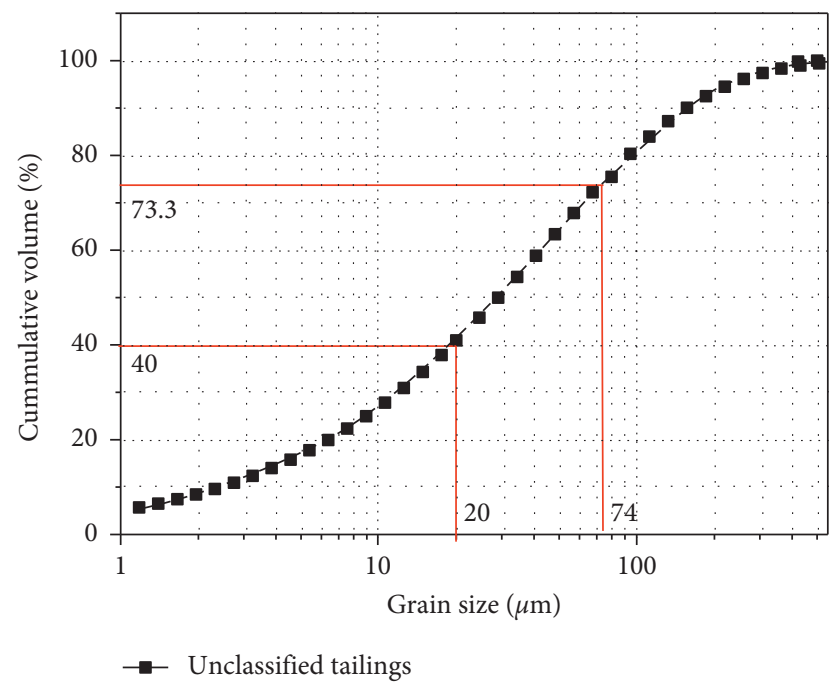

Figure 3: The particle size distribution of unclassified tailings.

The pressure drop in fluidized bed can be calculated by the equation which fits the balance between the friction of particles and fluid and its net gravity. With the flow velocity speeding up, the bed height and porosity $\varepsilon$ increase together, but $\Delta p$ stays the same. The pressure drop for the whole fluidized bed is

$$
\Delta p_{f}=H_{m f}\left(\rho_{s}-\rho\right)\left(1-\varepsilon_{m f}\right) g,
$$

where $\Delta p_{f}$ is the pressure drop in the fluidized bed, $\mathrm{Pa} ; H_{m f}$ is the height of the initial-fluidized bed; $\varepsilon_{m f}$ is the porosity of the initial-fluidized bed; $\rho_{s}$ is the solid density of tailings; and $\rho$ is slurry density.

2.3. Critical Fluidized Velocity $U_{m f}$. For fine particles, we employ Carman-Kozeny formula to illustrate the relationship between the pressure drop and flow velocity in the initial-fluidized point [41].

$$
\Delta P_{f}=\frac{5\left(1-\varepsilon_{m f}\right)^{2}}{\varepsilon_{m f}^{3}} S_{0}^{2} \mu H_{m f} U_{m f},
$$

where $S_{0}$ is the particles specific surface area; $u$ is fluid viscosity; and $U_{m f}$ is the critical fluidized velocity.

$$
\begin{aligned}
\varepsilon_{m} & =1-C_{v m}, \\
C_{v m} & =\frac{1}{1+\left(\left(\left(1 / C_{w m}\right)-1\right)\left(\rho_{f} / \rho_{s}\right)\right)},
\end{aligned}
$$

where $C_{v m}$ is volume concentration; $C_{u m}$ is the weight concentration; and $\rho_{f}$ is the density of fluidized bed. Thus, we can figure out $C_{u m}$ and $C_{v m}$ after the process parameters are designed. Also, the critical fluidized velocity can be computed with the following equation:

$$
U_{m f}=\frac{g\left(\rho_{s}-\rho_{f}\right)}{5 S_{0}^{2} \mu} \frac{\varepsilon_{m f}^{3}}{1-\varepsilon_{m f}} .
$$

\section{Fluidization Reform of DCT}

3.1. Fluidization Arrangement and Parameters of Spray Nozzles. Tailings in Huize mine are finer with the average particle size of $75.6 \mu \mathrm{m}$ and the porosity of $36.4 \%$. The percentages of particle size of tailings less than $20 \mu \mathrm{m}$ and $74 \mu \mathrm{m}$ are $40 \%$ and $73.3 \%$, respectively. The distribution range of tailings grading is wide when the coefficient of uniformity $\mathrm{Cu}>5$, and tailings exhibit good gradation and a high compaction rate when the curvature coefficient $C c=1-3$. These tailings are well graded given that their $C u$ and $C c$ values are 17.6 and 1.3, respectively. Thus, these tailings benefit the paste preparation process. The tailings produced in Huize lead-zinc mine have certain cohesiveness and certain accumulation strength, which is easy to cause accidents of pressure rake and uneven concentration during tailings release. The particle size continuity of unclassified tailings is better, with a larger distribution range and uniform distribution, as shown in Figure 3.

In the process of using DCT to discharge slurry, the dehydration of tailings in the bonding zone will form a bonding zone on the lateral wall of the cone [38]. The bonding zone constitutes the funnel pipe for the discharging slurry with certain stacking strength, which is the main reason for the failure of thickener, uneven concentration of slurry, and other accidents. Near the central axis, the liquid level of the discharging funnel is lower, while the liquid level far from the central axis does not change, which causes the side surface of the discharging funnel to form the obvious hyperbolic shape. The spray nozzles are arranged along the side surface of the bonding zone, appearing inverted pyramid gradient, because the side surface of the funnel is the surface of a hyperbolic revolving body, as shown in Figure 4 . In order to form a uniform disturbed zone, it is considered that nozzles are arranged on stirring harrow.

The function of nozzle is to provide high-energy and high-speed fluid, form fluidization zone, reduce highconcentration tailings, and make them uniform. Highpressure water can not only disperse the agglomerated tailings but also provide water and reduce the system concentration. High-pressure gas only plays a role of 


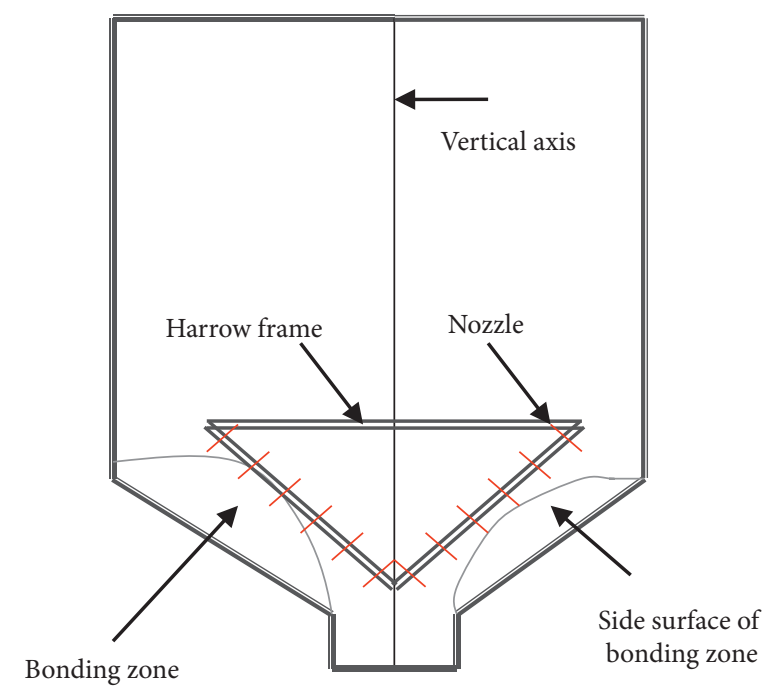

Figure 4: Simple view of the arrangement of spray nozzles.
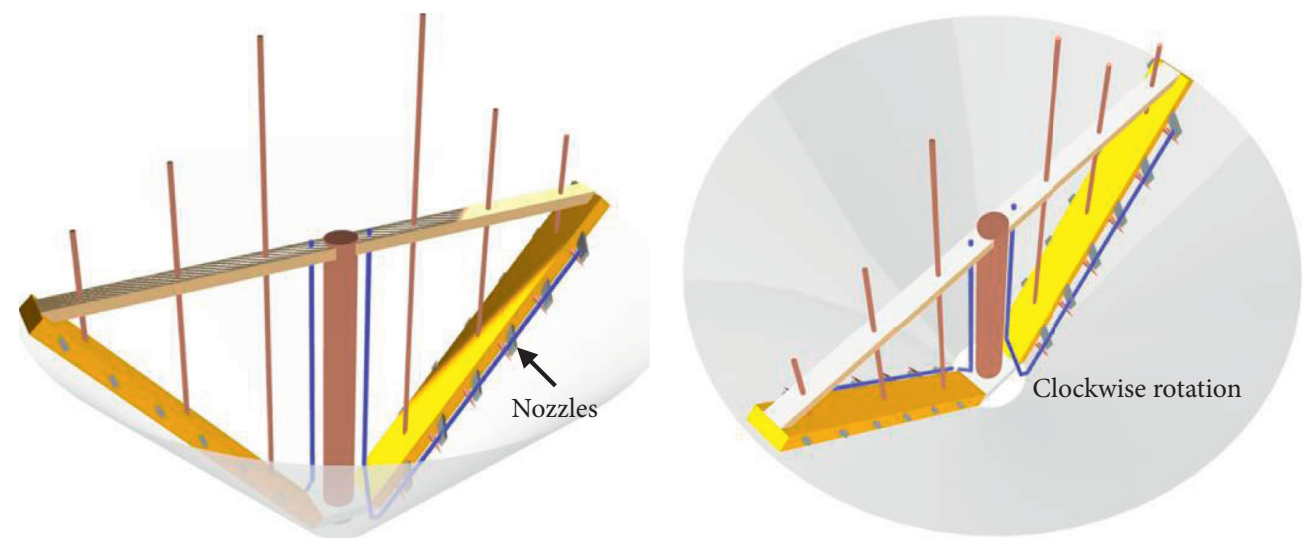

FIgure 5: Transformation in the middle of the system and rotation direction of the vertical axis.

dispersion and does not change the average concentration of the whole system.

3.2. Fluidization Parameters. In the ideal state, the larger the range of fluidization zone, the better the overall mobility of sand bodies and the more stable the system operation [42-44]. In the practical application, the maximum value of the solid bed height of the sand body was designed as $7 \mathrm{~m}$. According to the law of bed expansion, the height of the fluidized bed is

$$
H_{f}=\frac{\left(1-\varepsilon_{0}\right) H_{0}}{\left(1-\varepsilon_{f}\right)},
$$

where $H_{0}$ is the height of a fixed bed, m; $H_{f}$ is the height of the fluidized bed, $\mathrm{m}$; $\varepsilon_{0}$ is the porosity of fixed bed; and $\varepsilon_{f}$ is the porosity of fluidized bed.

Conduction of extreme settlement tests of tailings slurry shows the maximum concentration of tailings slurry was $82 \%$, which was employed as the concentration of the fixed bed, and the corresponding porosity was $39.7 \%$. According to the actual operation of the deep cone, when the concentration was $76 \%$, the fluidity of the slurry was the best, so the fluidized bed concentration was determined as $76 \%$ and the corresponding porosity was $46.0 \%$. According to formula (6), the height of the deep cone fluidized bed was $7.8 \mathrm{~m}$, and according to formulas $1-6$, the working pressure of nozzle was $0.432 \mathrm{MPa}$. Combining the rated discharge capacity and the volume concentration of the fixed bed, the nozzle flow rate was calculated as $5.86 \mathrm{~m}^{3} / \mathrm{h}$.

3.3. System Reform and Application Effect. Under the disturbance of the rake frame, the floc structure is broken, the closed water is released, and an upward migration channel is formed. The water content is reduced and the tailings concentration is further increased. The reform focus was the arrangement and number of spray nozzles. The vertical axis of DCT and harrow rotated in a clockwise direction, as shown in Figure 5. The nozzles were arranged at the front of the mud scraping plate, fixed on the inner side of the scraper and connected with the air supply pipe. The two wings were, respectively, installed on 6 nozzles, a total of 12. The metal pipe used for gas supply was fixed on the large harrow frame and rotated along with nozzles and harrow frame. 


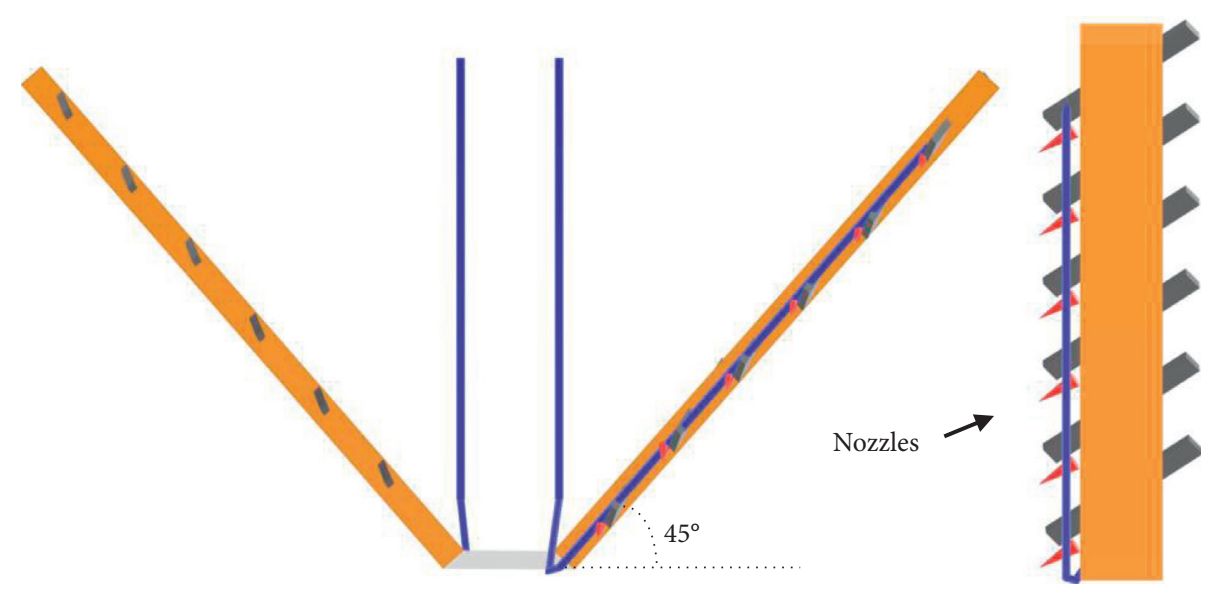

Figure 6: Arrangement plan of spray nozzles.

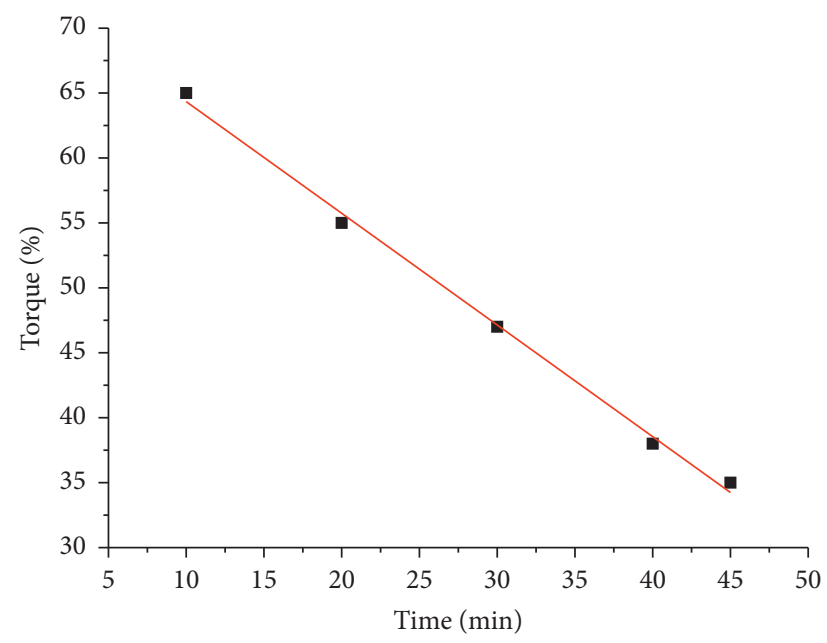

FIgURE 7: The variation of torque by time.

TABLE 1: Technical parameter statistics before and after the reform.

\begin{tabular}{|c|c|c|c|}
\hline Item & $\begin{array}{l}\text { Failure time of } \\
\text { thickener }(\mathrm{h})\end{array}$ & $\begin{array}{l}\text { The concentration of slurry at the } \\
\text { bottom }(\%)\end{array}$ & Remarks \\
\hline $\begin{array}{l}\text { Before } \\
\text { reform }\end{array}$ & 14 & $74-79$ & $\begin{array}{c}\text { The concentration was not uniform and the fluctuation } \\
\text { range was bigger. }\end{array}$ \\
\hline $\begin{array}{l}\text { After } \\
\text { reform }\end{array}$ & 1 & $78-80$ & $\begin{array}{c}\text { The concentration was more uniform and stable at about } \\
78 \% .\end{array}$ \\
\hline
\end{tabular}

The specific arrangement of the nozzles is shown in Figure 6. The nozzles were fixed on the inner side of the scraping plate and connected with an air supply pipe. And their direction, between which and the horizontal plane was $45^{\circ}$, was parallel to the scraping plate.

When a failure of the deep cone thickener occurs, open the underflow pump to discharge the high-concentration slurry at the bottom of the cone. After the slurry level fell to the conical part, open the nozzle device. At this time, the torque of the scraper was observed to become smaller (generally decreased from about $60 \%$ to about $30 \%$ ) and there were bubbles in the overflow area in the upper part of the cone. Compressing air for about half an hour, the system was restarted and the mud scraping harrow was normally operated. Figure 7 shows the change of the deep cone torque observed by the DCS control room after opening the nozzle device.

Through the above method, the failure time of thickener was decreased from 14 hours to 1 hour, greatly improving the work efficiency. Meanwhile, the high-pressure process made the particles uniform and easy to control in the cone. The underflow concentration was generally maintained at around $78 \%$, in line with the requirements of paste preparation. Technical parameter statistics before and after reform are shown in Table 1. 


\section{Conclusions}

Through the study of the motion state of unclassified tailings in the DCT, the movement discipline of tailings was analyzed. By fluidization theory, fluidization design was conducted for the deep cone system in Huize mine. Field operation shows that fluidization design decreased the failure time of the thickener from 14 hours to 1 hour, improved the stability of the deep cone thickener, and provided reference values for similar mines.

\section{Data Availability}

The data used to support the findings of this study are included within the article.

\section{Conflicts of Interest}

The authors declare that they have no conflicts of interest.

\section{Acknowledgments}

This study was financially supported by the China Postdoctoral Science Foundation (2019M663576), National Natural Science Foundation of China (51934003 and 51774020), Program for Yunnan Thousand Talents Plan High-level Innovation and Entrepreneurship Team, and Program for Innovative Research Team (in Science and Technology) in University of Yunnan Province.

\section{References}

[1] C. Qi, A. Fourie, Q. Chen, X. Tang, Q. Zhang, and R. Gao, "Data-driven modelling of the flocculation process on mineral processing tailings treatment," Journal of Cleaner Production, vol. 196, pp. 505-516, 2018.

[2] A. Wu, H. Li, H. Cheng, Y. Wang, C. Li, and Z. Ruan, "Status and prospects of researches on rheology of paste backfill using unclassified-tailings (part 1): concepts, characteristics and models," Chinese Journal of Engineering, 2020, In press.

[3] A. Fourie, "Preventing catastrophic failures and mitigating environmental impacts of tailings storage facilities," Procedia Earth and Planetary Science, vol. 1, no. 1, pp. 1067-1071, 2009.

[4] C. Qi and A. Fourie, "Cemented paste backfill for mineral tailings management: review and future perspectives," Minerals Engineering, vol. 144, Article ID 106025, 2019.

[5] H. Cheng, S. Wu, H. Li, and X. Zhang, "Influence of time and temperature on rheology and flow performance of cemented paste backfill," Construction and Building Materials, vol. 231, Article ID 117117, 2020.

[6] H. Cheng, S. Wu, X. Zhang, and J. Li, "A novel prediction model of strength of paste backfill prepared from wasteunclassified tailings," Advances in Materials Science and Engineering, vol. 2019, Article ID 3574190, 10 pages, 2019.

[7] M. Fall, D. Adrien, J. C. Célestin, M. Pokharel, and M. Touré, "Saturated hydraulic conductivity of cemented paste backfill," Minerals Engineering, vol. 22, no. 15, pp. 1307-1317, 2009.

[8] C. Qi, Q. Chen, A. Fourie et al., "Constitutive modelling of cemented paste backfill: a data-mining approach," Construction and Building Materials, vol. 197, pp. 262-270, 2019.

[9] C. Qi, L. Liu, J. He, Q. Chen, L.-J. Yu, and P. Liu, "Understanding cement hydration of cemented paste backfill: DFT study of water adsorption on tricalcium silicate (111) surface," Minerals, vol. 9, no. 4, p. 202, 2019.

[10] A. Wu, Y. Yang, H. Cheng, S. Chen, and Y. Han, "Status and prospects of paste technology in China," Chinese Journal of Engineering, vol. 40, no. 5, pp. 517-525, 2018.

[11] H.-y. Cheng, S.-c. Wu, X.-q. Zhang, and A.-x. Wu, "Effect of particle gradation characteristics on yield stress of cemented paste backfill," International Journal of Minerals, Metallurgy and Materials, vol. 27, no. 1, pp. 10-17, 2020.

[12] S. Cao, G. Xue, W. Song, and Q. Teng, "Strain rate effect on dynamic mechanical properties and microstructure of cemented tailings composites," Construction and Building Materials, vol. 247, Article ID 118537, 2020.

[13] N. Jiang, C. Wang, H. Pan, D. Yin, and J. Ma, "Modeling study on the influence of the strip filling mining sequence on mining-induced failure," Energy Science \& Engineering, vol. 8, no. 6, pp. 2239-2255, 2020.

[14] Z. Xue, D. Gan, Y. Zhang, and Z. Liu, "Rheological behavior of ultrafine-tailings cemented paste backfill in high-temperature mining conditions," Construction and Building Materials, vol. 253, Article ID 119212, 2020.

[15] Y. Yang, T. Zhao, H. Jiao, Y. Wang, and H. Li, "Potential effect of porosity evolution of cemented paste backfill on selective solidification of heavy metal ions," International Journal of Environmental Research and Public Health, vol. 17, no. 3, p. 814, 2020.

[16] R. Buscall, P. J. Scales, A. D. Stickland, H.-E. Teo, and D. R. Lester, "Dynamic and rate-dependent yielding in model cohesive suspensions," Journal of Non-newtonian Fluid Mechanics, vol. 221, pp. 40-54, 2015.

[17] R. van Berkel, "Eco-efficiency in the Australian minerals processing sector," Journal of Cleaner Production, vol. 15, no. 8-9, pp. 772-781, 2007.

[18] L. Gong-cheng, W. Hong-jiang, J. hua-zhe, S. Wei, and W. Ai-xiang, "Physical simulation of dewaterability law of unclassified tailings in steady state thickener," The Chinese Journal of Nonferrous Metals, vol. 29, no. 3, 2019.

[19] L. Gong-cheng, W. Hong-jiang, W. Ai-xiang, J. Hua-zhe, and W. Fang-zheng, "Analysis of thickening performance of unclassified tailings in rakeless deep cone thickener," Chinese Journal of Engineering, vol. 41, no. 1, pp. 60-66, 2019.

[20] J. Huazhe, W. Shufei, Y. Yixuan, and C. Xinming, "Water recovery improvement by shearing of gravity-thickened tailings for cemented paste backfill," Journal of Cleaner Production, vol. 245, p. 118882, 2019.

[21] S. Cao, E. Yilmaz, W. Song, E. Yilmaz, and G. Xue, "Loading rate effect on uniaxial compressive strength behavior and acoustic emission properties of cemented tailings backfill," Construction and Building Materials, vol. 213, pp. 313-324, 2019.

[22] D. Xie, X. Tong, X. Xie, K. Hou, and L. I. Jiyong, "The application and development of thickener in mineral processing technology," Conservation \& Utilization of Mineral Resources, vol. 4, no. 2, pp. 73-78, 2015.

[23] H. Cheng, S. Wu, A. Wu, and W. Cheng, "Grading characterization and yield stress prediction based on paste stability coefficient," Chinese Journal of Engineering, vol. 40, no. 10, pp. 1168-1176, 2018.

[24] A. Wu, Z. Ruan, R. Bürger, S. Yin, J. Wang, and Y. Wang, "Optimization of flocculation and settling parameters of tailings slurry by response surface methodology," Minerals Engineering, vol. 156, Article ID 106488, 2020.

[25] H. Jiao, Y. Wu, X. Chen, and Y. Yang, "Flexural toughness of basalt fibre-reinforced shotcrete and industrial-scale testing," 
Advances in Materials Science and Engineering, vol. 2019, Article ID 6568057, 8 pages, 2019.

[26] H.-z. Jiao, S.-f. Wang, A.-x. Wu, H.-m. Shen, and J.-d. Wang, "Cementitious property of $\mathrm{NaAlO}_{2}$-activated Ge slag as cement supplement," International Journal of Minerals, Metallurgy and Materials, vol. 26, no. 12, pp. 1594-1603, 2019.

[27] X. Chen, X. Jin, H. Jiao, Y. Yang, and J. Liu, "Pore connectivity and dewatering mechanism of tailings bed in raking deepcone thickener process," Minerals, vol. 10, no. 4, p. 375, 2020.

[28] Y. Wang, A. X. Wu, H. J. Wang, and B. Zhou, "Dynamic thickening characteristics and mathematical model of total tailings," Rock \& Soil Mechanics, vol. 35, pp. 168-179, 2014.

[29] D. Wu, M. Fall, and S. J. Cai, "Coupling temperature, cement hydration and rheological behaviour of fresh cemented paste backfill," Minerals Engineering, vol. 42, pp. 76-87, 2013.

[30] S. Yin, A. Wu, K. Hu, Y. Wang, and Y. Zhang, "The effect of solid components on the rheological and mechanical properties of cemented paste backfill," Minerals Engineering, vol. 35, pp. 61-66, 2012.

[31] J. C. Serbon, L. Mac-Namara, and F. Schoenbrunn, "Application of the FLSmidth deep cone technology to the fertilizer plants in OCP," Procedia Engineering, vol. 138, pp. 314-318, 2016.

[32] C. K. Tan, R. Setiawan, J. Bao, and G. Bickert, "Studies on parameter estimation and model predictive control of paste thickeners," Journal of Process Control, vol. 28, pp. 1-8, 2015.

[33] B. R. Gladman, M. Rudman, and P. J. Scales, "Experimental validation of a 1-D continuous thickening model using a pilot column," Chemical Engineering Science, vol. 65, no. 13, pp. 3937-3946, 2010.

[34] T. Zhou, M. Li, C.-q. Zhou, and J.-m. Zhou, "Numerical simulation and optimization of red mud separation thickener with self-dilute feed," Journal of Central South University, vol. 21, no. 1, pp. 344-350, 2014.

[35] H. Z. Jiao, A. X. Wu, H. J. Wang, X. H. Liu, and Y. T. Xiao, "Experiment study on the flocculation settlement characteristic of unclassified tailings," Journal of University of Science \& Technology Beijing, vol. 33, no. 12, pp. 1437-1441, 2011.

[36] R. Setiawan, C. Keong Tan, J. Bao, and G. Bickert, "Model predictive control of a paste thickener in coal handling and preparation plants," IFAC Proceedings Volumes, vol. 46, no. 32, pp. 247-252, 2013.

[37] Y. Zhang, P. Grassia, A. Martin, S. P. Usher, and P. J. Scales, "Mathematical modelling of batch sedimentation subject to slow aggregate densification," Chemical Engineering Science, vol. 128, pp. 54-63, 2015.

[38] L. I. Hui, H. J. Wang, W. U. Ai-Xiang, H. Z. Jiao, and X. H. Liu, "Pressure rake analysis of deep cone thickeners based on tailings' settlement and rheological characteristics," Journal of University of Science \& Technology Beijing, vol. 35, no. 12, pp. 1553-1558, 2013.

[39] W. Hong-jiang, C. Qin-rui, W. Ai-xiang, Z. Yong-gang, and Z. Xin-pu, "Study on the thickening properties of unclassified tailings and its application to thickener design," Journal of University of Science \& Technology Beijing, vol. 33, no. 6, pp. 676-681, 2011.

[40] A. T. Owen, T. V. Nguyen, and P. D. Fawell, "The effect of flocculant solution transport and addition conditions on feedwell performance in gravity thickeners," International Journal of Mineral Processing, vol. 93, no. 2, pp. 115-127, 2009.

[41] M. Rudman, K. Simic, D. A. Paterson, P. Strode, A. Brent, and I. D. Šutalo, "Raking in gravity thickeners," International Journal of Mineral Processing, vol. 86, no. 1-4, pp. 114-130, 2008.
[42] C. Hui, H. Wang, A. Wu, and Y. Wang, "Application and revamping of deep cone thickener on a mine in harbin," Metal Mine, vol. 44, no. 5, pp. 158-161, 2015.

[43] A. S. Atkins, A. Barkhordarian, R. N. Singh, and A. H. Zadeh, "Pumpability of coal mine tailings for underground disposal and for regional support,"Advances in Mining Science and Technology, vol. 2, pp. 401-414, Elsevier, Amsterdam, Netherlands, 1987.

[44] M. Rahimi, A. A. Abdollahzadeh, and B. Rezai, "Dynamic simulation of tailing thickener at the Tabas coal washing plant using the phenomenological model," International Journal of Mineral Processing, vol. 154, pp. 35-40, 2016. 